\title{
In Vitro Toxicokinetics and Phase I Biotransformation of the Mycotoxin Penitrem A in Dogs
}

\author{
Silvio Uhlig ${ }^{1, *(\mathbb{D}}$, Lada Ivanova ${ }^{1}$, Pauline Voorspoels ${ }^{2}$ and Christiane Kruse Fæste ${ }^{1}$ \\ 1 Toxinology Research Group, Norwegian Veterinary Institute, Ullevålsveien 68, 0454 Oslo, Norway; \\ lada.ivanova@vetinst.no (L.I.); christiane.faste@vetinst.no (C.K.F.) \\ 2 Department of Bioanalysis, Faculty of Pharmaceutical Sciences, Ghent University, Ottergemsesteenweg 460, \\ 9000 Gent, Belgium; pauline.voorspoels@gmail.com \\ * Correspondence: silvio.uhlig@vetinst.no
}

Received: 25 February 2020; Accepted: 29 April 2020; Published: 4 May 2020

\begin{abstract}
The tremorgenic mycotoxin penitrem A is produced by Penicillium species as a secondary metabolite on moldy food and feed. Dogs are sometimes exposed to penitrem A by consumption of spoiled food waste or fallen fruit. The lipophilic toxin crosses the blood-brain barrier and targets neuroreceptors and neurotransmitter release mechanisms in the central and peripheral nervous systems. Typical symptoms of penitrem A intoxication are periodical or continuous tremors, which can be passing, persistent or lethal, depending on the absorbed dose. There is presently no information on the biotransformation and toxicokinetics of penitrem A in dogs. The aim of the present study was therefore to identify potential metabolites of the toxin by performing in vitro biotransformation assays in dog liver microsomes. Analyses by liquid chromatography coupled to high-resolution mass spectrometry led to the provisional identification of eleven penitrem A phase I metabolites, which were tentatively characterized as various oxidation products. Furthermore, elimination parameters determined in in vitro assays run under linear kinetics were used for in vitro-to-in vivo extrapolation of the toxicokinetic data, predicting a maximal bioavailability of more than $50 \%$. The metabolite profile detected in the in vitro assays was similar to that observed in the plasma of an intoxicated dog, confirming the predictive capability of the in vitro approach.
\end{abstract}

Keywords: dogs; in vitro; liver microsomes; metabolite identification; penitrem A; poisoning; toxicokinetics

Key Contribution: Penitrem A biotransformation in dogs was studied in vitro using liver microsomes, and oxygenated metabolites were characterized by high-resolution mass spectrometry. In vitro-to-in vivo extrapolation predicted substantial bioavailability of penitrem A after oral uptake and a sufficiently long elimination half-life, allowing for considerable persistence of the plasma levels.

\section{Introduction}

Penitrem A (Figure 1) is a toxic secondary metabolite of Penicillium crustosum, a fungus adapted to all climate zones that occurs mainly on spoiled food and feed [1,2]. It has, however, also been found on Poa huecu grass and in soil samples [3,4]. Intoxication with penitrem A from the ingestion of moldy foodstuffs or contaminated grass causes neurological symptoms, in which the severity and persistence depend directly on the level of exposure [5]. The mycotoxin can pass through the blood-brain barrier into the central nervous system, where it affects the GABAergic neurotransmission, blocks potassium channels and causes cell death [6,7]. Neurological effects such as activity suppression, lethargy and cataleptic behavior can occur as early as $30 \mathrm{~s}$ after uptake, followed by irritability, hyperresponsiveness 
to external stimuli (e.g., touch and noise) and muscle tremors, weakness and rigidity, which can proceed further to opisthotonus, mydriasis, nystagmus, convulsions and ataxia, and ultimately death [8-10].

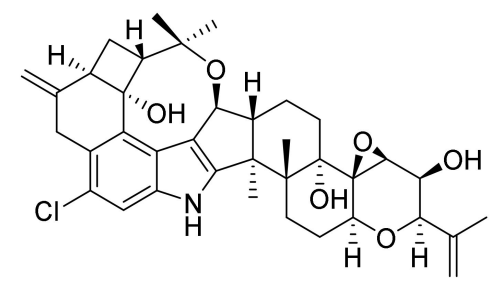

Figure 1. Chemical structure of the fungal neurotoxin penitrem A.

Cases of suspected penitrem A-induced human mycotoxicosis are rare. The few known incidents are connected to the consumption of spoiled beer, food or inhalation from moldy silage [9,11]. "Huecu's disease", a ryegrass stagger-like syndrome, has been observed in Argentina in grazing animals including sheep, horses, cattle and goats [5]. Penitrem A intoxication affects, however, most frequently dogs due to their easy access to food waste and moldy fruit [11-21]. In addition to the neurological symptoms, penitrem A toxicosis in dogs is typically also accompanied by excessive salivation, vomiting, frequent urination and defecation, panting, metabolic acidosis and hyperthermia [1,10,13,22]. Depending on the level of toxin exposure, dogs recover after weeks or maybe months, but in severe cases, the coordination of muscle movements may still be impaired even after years [20]. As antidotes are not available, only alleviating care is possible, for example, by administration of activated charcoal, diazepam or barbiturates [10,23]. The marine drugs astaxanthin and docosahexaenoic acid have shown some effectiveness in counter-acting penitrem A-related cytotoxicity when applied preventively, but a curative treatment after intoxication has not been developed [24].

Penitrem A is a decacyclic indole-diterpenoid derived from the biosynthetic intermediate paspaline in a multi-step reaction pathway (Figure 1). The penitrem A molecule contains a fused cyclohexyl-cyclobutyl ring that is formed by two cyclized isoprene units attached to a tryptophan-derived indole moiety [6,9]. Functional groups include hydroxyl groups, chlorine and an epoxide ring.

Analytical methods for the selective determination of penitrem A in cell cultures, serum, urine, vomit, liver, brain, intestine and different foodstuffs most often make use of high performance liquid chromatography-tandem mass spectrometry (HPLC-MS/MS) [16,25-29]. After extraction from the matrix and clean-up, the toxin was separated by reversed-phase LC, ionized by positive electrospray ionization (ESI) or atmospheric pressure chemical ionization (APCI), fragmented by collision-induced dissociation (CID) and detected by triple quadrupole or linear ion trap MS/MS. Detection limits ranging from $0.7 \mu \mathrm{g} / \mathrm{kg}$ in cheese, $1 \mu \mathrm{g} / \mathrm{kg}$ in serum and urine to $5 \mu \mathrm{g} / \mathrm{kg}$ in a food mixture and different organs have been achieved. The penitrem A molecule loses water during ionization and produces characteristic product ions in MS/MS analyses that are used for unambiguous identification [27].

The lipophilic toxin is rapidly absorbed from the gastrointestinal tract after the ingestion of contaminated foodstuff [9]. Taking the onset of the neurological effects as an indicator, maximum plasma concentrations are probably reached within 30 min in mice, rats, dogs, sheep, pigs and cows. Penitrem A is quickly distributed to most body compartments, reaching its main site of action in the brain [28]. Biotransformation of the toxin has been studied in vivo in mice and in vitro with rat liver microsomes and primary hepatocytes [27], showing the formation of oxidized metabolites with increased hydrophilicity. Conjugation products were not observed, although excretion via bile and feces has been suggested as the main route of excretion [21].

Although intoxication of dogs is by far the most frequent adverse incident connected to penitrem A, information on the toxin's biotransformation and toxicokinetics in dogs is presently not available. It was therefore the aim of the present study to determine potential products of the canine penitrem A metabolism and use in vitro-to-in vivo extrapolation (IVIVE) to predict main kinetic parameters [30]. 


\section{Results and Discussion}

\subsection{Mass Spectrometric Fragmentation of Penitrem A}

The mass spectrometric fragmentation of penitrem $\mathrm{A}\left(\mathrm{C}_{37} \mathrm{H}_{44} \mathrm{NO}_{6} \mathrm{Cl}\right.$; exact mass of protonated molecules $634.2930 \mathrm{~m} / \mathrm{z}$ ) has been studied previously using collision-induced dissociation (CID) in a low-resolution ion-trap instrument [27]. CID resulted in sequential losses of water and acetone, and the mass spectra did not show any ions with significant signal intensities below $m / z 500$. Higher-energy collision dissociation (HCD) is a complementary technique that often results in more complex fragmentation, which may yield more structural information. We used HCD in a high-resolution tandem mass spectrometer (HRMS/MS) resulting in product ions over the entire mass range (Figure 2). While the principal product ion from CID was observed at $m / z 558$ [27], this ion was of medium intensity in the HCD HRMS/MS spectrum (Figure 2). However, the high-resolution approach verified that the product ion at $m / z 558$ was the result of sequential loss of acetone and water $\left(-\mathrm{C}_{3} \mathrm{H}_{8} \mathrm{O}_{2}\right.$, i.e., $\left.-\left(\mathrm{C}_{3} \mathrm{H}_{6} \mathrm{O}+\mathrm{H}_{2} \mathrm{O}\right)\right)$ (Table 1). Furthermore, the transition from $\mathrm{m} / \mathrm{z} 634$ to $\mathrm{m} / \mathrm{z} 558$ has been used for the LC-MS/MS based quantitative penitrem A analyses in different matrixes, while $\mathrm{m} / \mathrm{z} 616$ and $\mathrm{m} / \mathrm{z} 540$ were detected as qualifier ions [26,29].

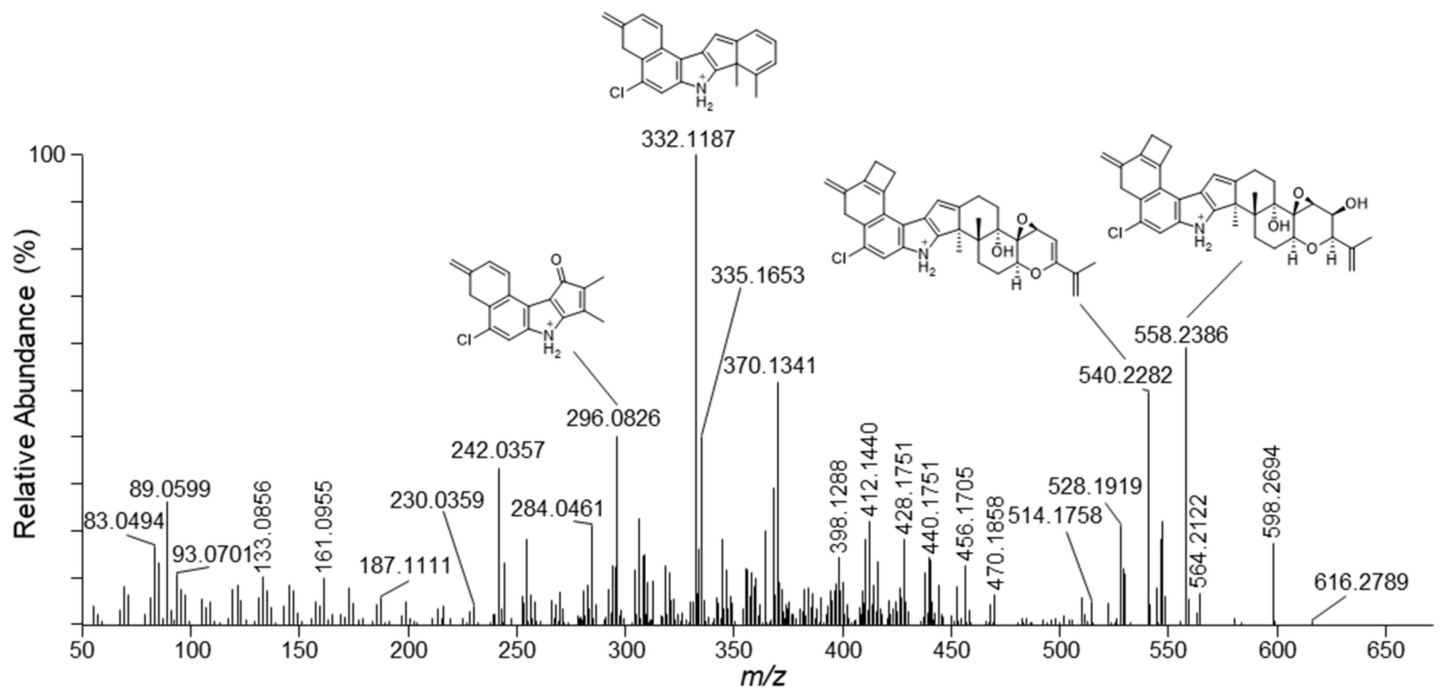

Figure 2. Product ion spectrum from higher-energy collision dissociation $(\mathrm{HCD})$ of the $[\mathrm{M}+\mathrm{H}]^{+}$ions of penitrem $\mathrm{A}\left({ }^{35} \mathrm{Cl}\right.$ isotopologue) including plausible structures of major fragment ions.

Table 1. HCD-generated main product ions of protonated penitrem $\mathrm{A}\left({ }^{35} \mathrm{Cl}\right.$ isotopologue) including calculated elemental compositions, mass errors, ring double bond equivalents and suggestions for possible neutral losses.

\begin{tabular}{ccccc}
\hline$m / z$ & Formula & $\Delta m(\mathbf{p p m})$ & RDBeq & Neutral Loss \\
\hline 616.2789 & $\mathrm{C}_{37} \mathrm{H}_{43} \mathrm{NO}_{5} \mathrm{Cl}$ & -5.7 & 16.5 & $\mathrm{H}_{2} \mathrm{O}$ \\
598.2694 & $\mathrm{C}_{37} \mathrm{H}_{41} \mathrm{NO}_{4} \mathrm{Cl}$ & -4.1 & 17.5 & $2 \times \mathrm{H}_{2} \mathrm{O}$ \\
564.2122 & $\mathrm{C}_{32} \mathrm{H}_{35} \mathrm{NO}_{6} \mathrm{Cl}$ & -4.5 & 15.5 & $\mathrm{C}_{5} \mathrm{H}_{10}$ \\
558.2386 & $\mathrm{C}_{34} \mathrm{H}_{37} \mathrm{NO}_{4} \mathrm{Cl}$ & -3.5 & 16.5 & $\mathrm{H}_{2} \mathrm{O}+\mathrm{C}_{3} \mathrm{H}_{6}(\mathrm{O})^{2}$ \\
540.2282 & $\mathrm{C}_{34} \mathrm{H}_{35} \mathrm{NO}_{3} \mathrm{Cl}$ & -3.2 & 17.5 & $2 \times \mathrm{H}_{2} \mathrm{O}+\mathrm{C}_{3} \mathrm{H}_{6}(\mathrm{O})^{2}$ \\
528.1919 & $\mathrm{C}_{32} \mathrm{H}_{31} \mathrm{NO}_{4} \mathrm{Cl}$ & -3.2 & 17.5 & $2 \times \mathrm{H}_{2} \mathrm{O}+\mathrm{C}_{5} \mathrm{H}_{10}$ \\
428.1751 & $\mathrm{C}_{28} \mathrm{H}_{27} \mathrm{NOCl}$ & -5.8 & 15.5 & $2 \times \mathrm{H}_{2} \mathrm{O}+\mathrm{C}_{3} \mathrm{H}_{6}(\mathrm{O})^{2}+\mathrm{C}_{6} \mathrm{H}_{8} \mathrm{O}_{2}$ \\
412.1440 & $\mathrm{C}_{27} \mathrm{H}_{23} \mathrm{NOCl}$ & -5.5 & 16.5 & $2 \times \mathrm{H}_{2} \mathrm{O}+\mathrm{C}_{3} \mathrm{H}_{6}(\mathrm{O})^{2}+\mathrm{C}_{6} \mathrm{H}_{8} \mathrm{O}_{2}+\mathrm{CH}_{4}$ \\
370.1341 & $\mathrm{C}_{25} \mathrm{H}_{21} \mathrm{NCl}$ & -4.3 & 15.5 & \\
332.1187 & $\mathrm{C}_{22} \mathrm{H}_{19} \mathrm{NCl}$ & -4.1 & 13.5 & \\
296.0826 & $\mathrm{C}_{18} \mathrm{H}_{15} \mathrm{NOCl}$ & -3.6 & 11.5 & \\
242.0357 & $\mathrm{C}_{14} \mathrm{H}_{9} \mathrm{NOCl}$ & -4.2 & 10.5 & \\
\hline \multicolumn{7}{c}{ Ring double bond equivalents. ${ }^{2}$ Acetone. }
\end{tabular}


HCD generated several product ions that were the result of cleavage across the cyclic backbone of penitrem A. Examples for conceivable structures of the corresponding product ions are shown in Figure 2. The rationale behind studying the HRMS/MS spectrum of penitrem A was to apply the acquired data for the subsequent extraction of putative biotransformation products from all-ion-fragmentation (AIF) chromatograms.

\subsection{Analysis of Penitrem A Metabolites Produced by In Vitro Biotransformation}

Potential penitrem A metabolites produced by dog liver microsomes were characterized based on the detailed analysis of the FullMS data for different incubation time points and AIF chromatograms, using the specific MS/MS product ions of penitrem A for comparison. This resulted in the tentative assignment of eleven penitrem A biotransformation products (Figure 3, Table 2). Their elemental composition differed from that of penitrem A by addition of one or two oxygen atoms (M1_a-M1_e and M3_a-M3_c, respectively), formal addition of water (M2) or a combination of both (M4_a and M4_b) (Figure 3, Table 2). Isomeric metabolites with identical molecular formulae but different retention times $\left(t_{R}\right)$ were designated with identical metabolite numbers but with consecutive alphabetical suffixes. The main metabolites after incubation for one hour were mono-oxygenated $(\mathrm{m} / \mathrm{z} 650.2858-650.2876)$ and mono-oxygenated/hydrated species ( $m / z$ 668.2984-668.2987).
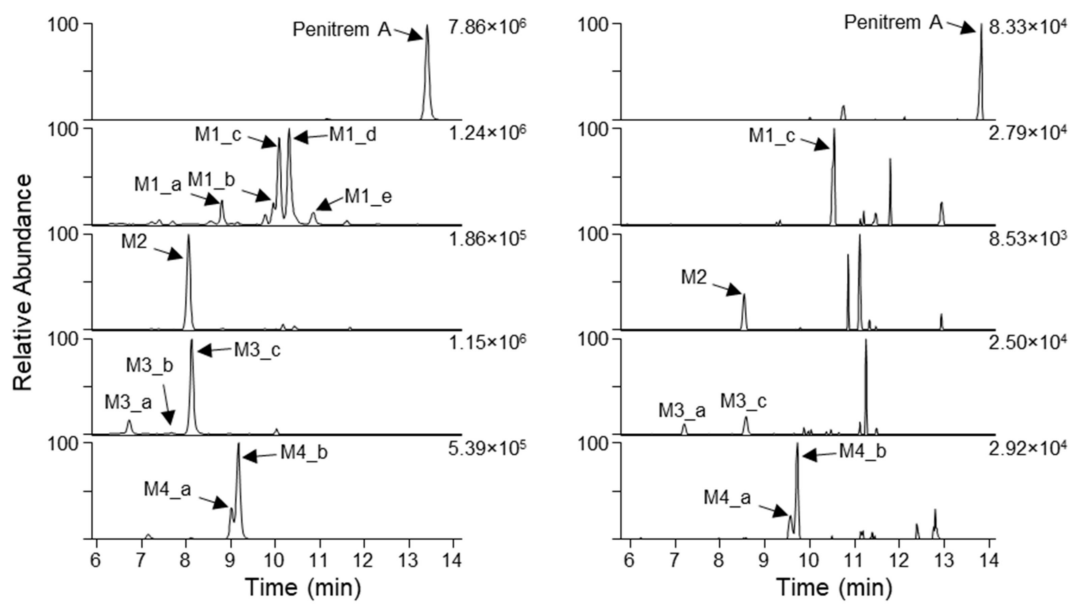

Figure 3. Extracted ion LC-HRMS chromatograms $( \pm 3.0 \mathrm{ppm})$ for $[\mathrm{M}+\mathrm{H}]^{+}$of penitrem $\mathrm{A}$ and putative phase I metabolites produced by incubation with dog liver microsomes (60 min, left panel) and in a plasma sample from an intoxicated dog (right panel). The shift to slightly longer retention times in the case of the plasma sample was due to the use of a different UHPLC mixer volume. The intensities of the highest peak in each chromatogram are indicated in the upper right-hand corners (arbitrary units).

Table 2. LC-HRMS characteristics of putative biotransformation products of penitrem A in incubations with dog liver microsomes.

\begin{tabular}{ccccccc}
\hline Metabolite ID & $\mathbf{t}_{\mathbf{R}}(\mathbf{m i n})^{\mathbf{1}}$ & $\mathbf{m} / \boldsymbol{z}$ & Ion & Formula & $\Delta \boldsymbol{m}$ (ppm) & RDBeq $^{\mathbf{2}}$ \\
\hline Penitrem A & 13.42 & 634.2927 & {$[\mathrm{M}+\mathrm{H}]^{+}$} & $\mathrm{C}_{37} \mathrm{H}_{45} \mathrm{NO}_{6} \mathrm{Cl}$ & -0.46 & 16 \\
M1_a & 8.81 & 650.2875 & {$[\mathrm{M}+\mathrm{H}]^{+}$} & $\mathrm{C}_{37} \mathrm{H}_{45} \mathrm{NO}_{7} \mathrm{Cl}$ & -0.58 & 16 \\
M1_b & 9.97 & 650.2876 & {$[\mathrm{M}+\mathrm{H}]^{+}$} & $\mathrm{C}_{37} \mathrm{H}_{45} \mathrm{NO}_{7} \mathrm{Cl}$ & -0.44 & 16 \\
M1_c & 10.09 & 650.2858 & {$[\mathrm{M}+\mathrm{H}]^{+}$} & $\mathrm{C}_{37} \mathrm{H}_{45} \mathrm{NO}_{7} \mathrm{Cl}$ & -3.5 & 16 \\
M1_d & 10.31 & 650.2865 & {$[\mathrm{M}+\mathrm{H}]^{+}$} & $\mathrm{C}_{37} \mathrm{H}_{45} \mathrm{NO}_{7} \mathrm{Cl}$ & -2.2 & 16 \\
M1_e & 10.87 & 650.2868 & {$[\mathrm{M}+\mathrm{H}]^{+}$} & $\mathrm{C}_{37} \mathrm{H}_{45} \mathrm{NO}_{7} \mathrm{Cl}$ & -1.6 & 16 \\
M2 & 8.06 & 652.3046 & {$[\mathrm{M}+\mathrm{H}]^{+}$} & $\mathrm{C}_{37} \mathrm{H}_{47} \mathrm{NO}_{7} \mathrm{Cl}$ & 1.6 & 15 \\
M3_a & 6.73 & 666.2834 & {$[\mathrm{M}+\mathrm{H}]^{+}$} & $\mathrm{C}_{37} \mathrm{H}_{45} \mathrm{NO}_{8} \mathrm{Cl}$ & 0.81 & 16 \\
M3_b & 7.67 & 666.2831 & {$[\mathrm{M}+\mathrm{H}]^{+}$} & $\mathrm{C}_{37} \mathrm{H}_{45} \mathrm{NO}_{8} \mathrm{Cl}$ & 0.34 & 16 \\
M3_c & 8.13 & 666.2826 & {$[\mathrm{M}+\mathrm{H}]^{+}$} & $\mathrm{C}_{37} \mathrm{H}_{45} \mathrm{NO}_{8} \mathrm{Cl}$ & -0.39 & 16 \\
M4_a & 9.02 & 668.2984 & {$[\mathrm{M}+\mathrm{H}]^{+}$} & $\mathrm{C}_{37} \mathrm{H}_{47} \mathrm{NO}_{8} \mathrm{Cl}$ & -0.17 & 15 \\
M4_b & 9.18 & 668.2987 & {$[\mathrm{M}+\mathrm{H}]^{+}$} & $\mathrm{C}_{37} \mathrm{H}_{47} \mathrm{NO}_{8} \mathrm{Cl}$ & 0.28 & 15 \\
\hline
\end{tabular}

${ }^{1} t_{R}$ : retention time, ${ }^{2}$ ring double bond equivalents of the neutral molecule. 
Previously, up to five different hepatic penitrem A metabolites were observed either in vitro in incubations with rat liver microsomes or primary rat hepatocytes, or in vivo in mice after oral administration $[27,28]$. The samples were analyzed by low-resolution MS that did not allow the calculation of elemental compositions. However, the mass differences between penitrem $A$ and the observed putative hepatic metabolites in the rodent experiments were comparable to those observed for the dog liver microsomes in the present study, except for a putative oxidation/dehydration product that was only detected in the livers of exposed mice and observed with a mass difference of $-2 \mathrm{~m} / \mathrm{z}$ relative to penitrem A. The increased number of identified metabolites in our study could also arise from a notable difference in the chromatographic analysis. While the previously reported HPLC methods used more traditional separation columns that probably did not have the ability to separate different isomers, we used a UHPLC method that was optimized for improved chromatographic resolution (longer column, smaller particles, core-shell instead of fully porous material). It could therefore be possible that penitrem A was also metabolized into isomeric metabolites in the rodent models, but that the analytical methodologies were insufficient to determine these.

\subsection{Detection of Penitrem $A$ and Metabolites in Intoxicated Dogs}

In the course of the present study, we received samples from veterinary clinics of four dogs that showed signs of potential penitrem poisoning. It is unknown how much time had passed between the actual poisoning incident and the collection of samples. The samples consisted of either plasma or serum, and in addition, the stomach content of one dog. UHPLC-HRMS analyses showed that the stomach content of this dog was positive for penitrem A (data not shown). Six of the 11 penitrem A metabolites found in the dog liver microsomes could be confirmed in the plasma sample, while the stomach contents did not contain detectable amounts of metabolites, which is expected in this pre-systemic sample (Figure 3). Although signal intensities were too low for the acquisition of HRMS/MS spectra, we were able to tentatively identify penitrem A metabolites in blood plasma based on their accurate mass data and characteristic isotopic signature due to the presence of the chlorine atom. It has to be noted that penitrem A was more prominent in the extracted $[\mathrm{M}+\mathrm{H}]^{+}$ion chromatograms than any of the phase I metabolites. The peak height of metabolite M4_b relative to penitrem A was about $35 \%$, similar to that of M1_c, which was $33 \%$.

\subsection{HRMS/MS Analysis of Putative Penitrem A Metabolites}

Parallel reaction monitoring targeting the $[\mathrm{M}+\mathrm{H}]^{+}$ions of putative penitrem A biotransformation products showed that they followed the same fragmentation pathways as the parent compound (Figure 4; Table 1). Thus, typical lower-mass product ions such as $m / z 242.0368-242.0370\left(\mathrm{C}_{14} \mathrm{H}_{9} \mathrm{NOCl}^{+}\right)$and 296.0834-296.0841 $\left(\mathrm{C}_{18} \mathrm{H}_{15} \mathrm{NOCl}^{+}\right)$, which were major fragments in the HRMS/MS spectra of penitrem A, were suitable for metabolite identification. They were used for fragment filtering of chromatograms from all-ion-fragmentation during the semi-targeted analysis of the plasma, tissue extracts and stomach contents of the four dogs that were suspected to suffer from penitrem poisoning. Moreover, several of the major higher- and medium-mass penitrem A product ions, for example, $m / z 332.1187,540.2282$ and 558.2386 , showed mass shifts in the product ion spectra of the metabolites that gave limited information about the molecular sites of the different biotransformation reactions. For example, the $m / z 332.1187$ product ion of penitrem A was observed with a mass shift corresponding to an oxygen atom in the spectra of M1_a and M1_c (i.e., $m / z 348.1152$ and 348.1150, respectively) (Figure 4), suggesting that the oxygenation had taken place in the substituted indole part of the molecule (Figure 2). In contrast, for M1_b, the product ion was observed at $m / z$ 332.1201, indicating that the mono-oxygenation had not happened in the same moiety. The regioselectivity of the biotransformation reactions could, however, not be derived unambiguously from the MS/MS spectra because the dissociation energy required for breaking molecular bonds in the polycyclic penitrem A backbone is considerably higher than that needed to remove functional groups that were added by biotransformation reactions. Consequently, 
oxygen-containing functional groups (e.g. hydroxyl groups) will be lost during fragmentation before carbon-carbon bonds in the cyclic moieties of the molecular backbone are cleaved.

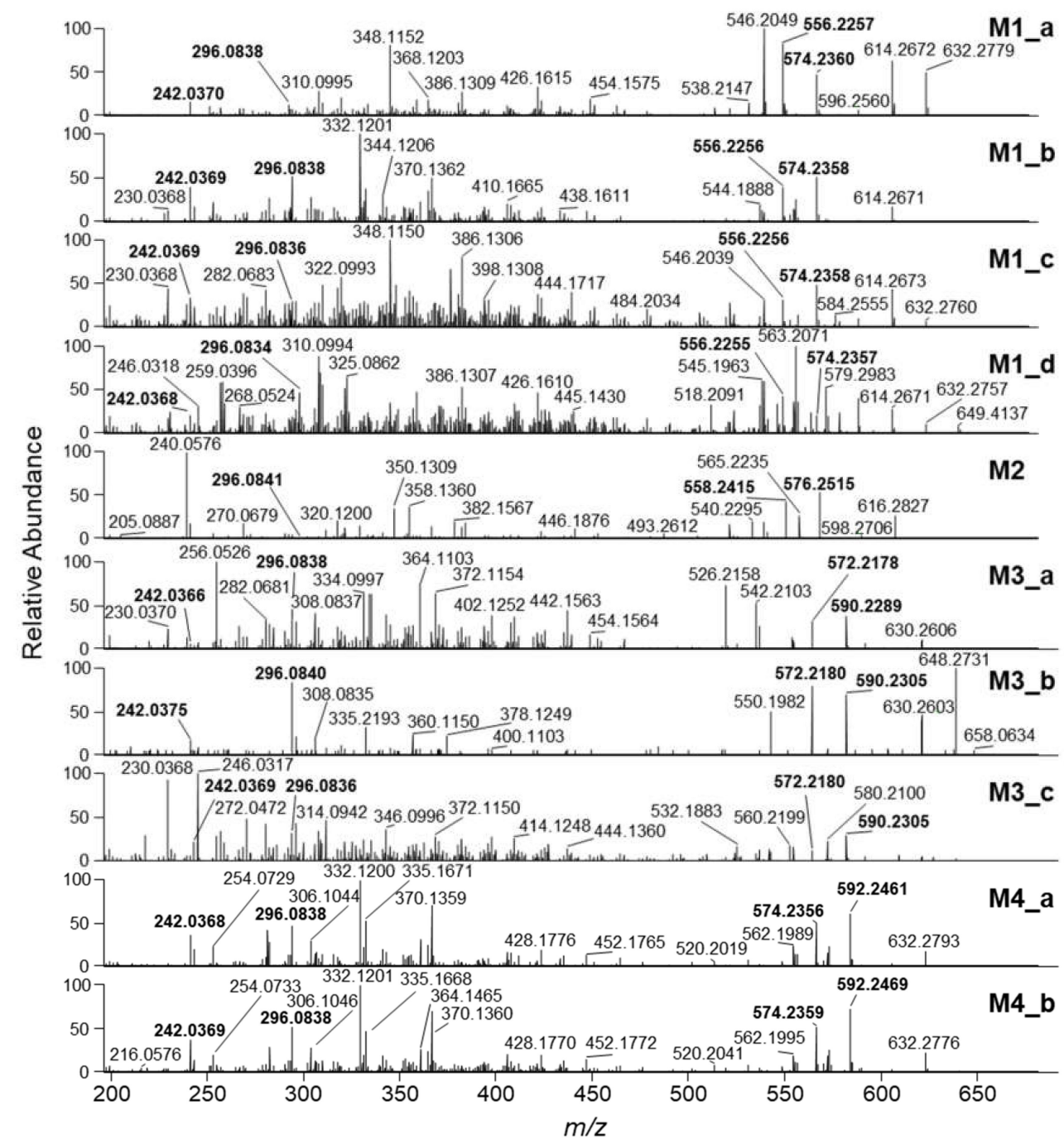

Figure 4. HRMS/MS product ion spectra from $\mathrm{HCD}$ of the $[\mathrm{M}+\mathrm{H}]^{+}$ions of putative penitrem A phase I metabolites produced in dog liver microsomes. Ions with $\mathrm{m} / \mathrm{z} 242.037$ and 296.084 were observed for all metabolites including penitrem A and could be suitable targets for penitrem A-specific fragment filtering. The bold-labeled higher-mass ions allowed distinguishing between the different metabolite types (i.e., $m / z 556.226$ and 574.236 for mono-oxygenated metabolites, $m / z 558.242$ and 576.252 for hydrated metabolites, $m / z 572.218$ and 592.229-592.231 for di-oxygenated metabolites, and $m / z 574.236$ and 592.246-592.247 for mono-oxygenated/hydrated metabolites). HRMS/MS spectra of good quality were not obtained for M1_e.

\subsection{Kinetics of Penitrem A Depletion in Dog Liver Microsomes}

In vitro metabolism experiments with liver microsomes or primary hepatocytes can be used for the prediction of in vivo kinetic parameters if the assays are conducted under first-order kinetics [30,31]. Under the condition that the substrate concentration in the assay is well below the reaction constant $\left(\mathrm{K}_{\mathrm{M} \text {,assay }}\right)$, the assay clearance $\left(\mathrm{CL}_{\text {assay }}\right)$ describing the elimination can be derived from the substrate depletion constant $\left(k_{e}\right)$. Therefore, as a first step, $k_{e}$ for five different initial penitrem A assay concentrations were determined by regression analysis of concentration versus time curves (Figure 5a). Secondly, we approximated $\mathrm{K}_{\mathrm{M} \text {,assay }}$ for penitrem $\mathrm{A}$ in incubations with dog liver microsomes as about $12 \mu \mathrm{M}$ from the inflection point of a concentration versus $\mathrm{k}_{\mathrm{e}}$ curve [32] (Figure 5b). All subsequent 
incubations were performed with starting concentrations of 1.2 or $2.5 \mu \mathrm{M}$ penitrem $\mathrm{A}$, thus fulfilling the requirements of linear kinetics.

a.

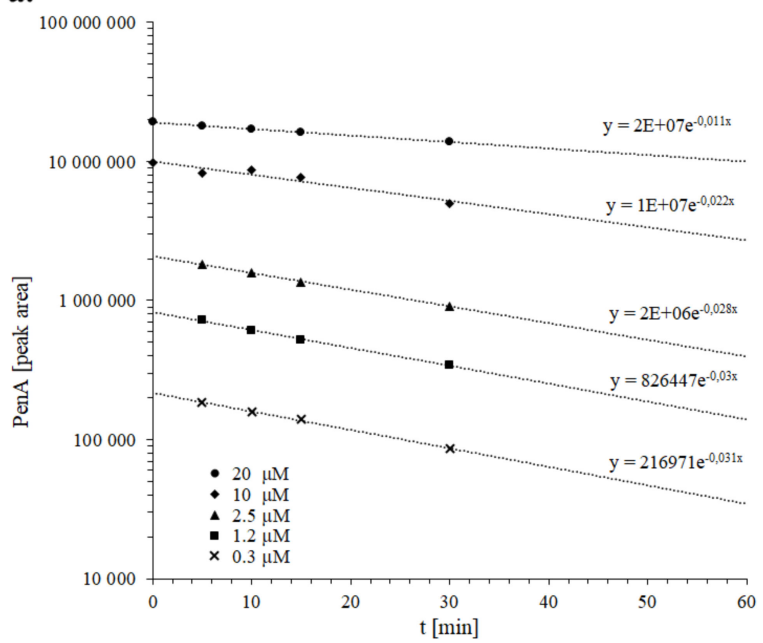

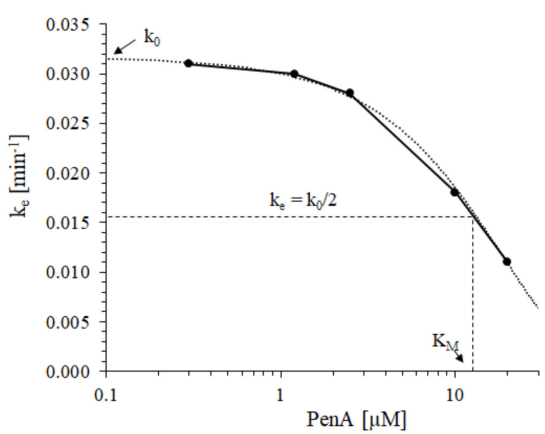

Figure 5. (a) Regression analysis for the determination of $k_{e}$ at different penitrem $A$ initial assay concentrations. (b) Approximation of $\mathrm{K}_{\mathrm{M}}$ for penitrem A in incubations with dog liver microsomes. Regression of the concentration versus $\mathrm{k}_{\mathrm{e}}$ curve allows convergence towards $\mathrm{k}_{0}$ at infinitesimally low substrate concentrations. The penitrem A concentration corresponding to $k_{0} / 2$ is equivalent to $K_{M}$.

\subsection{Prediction of Toxicokinetic Parameters for Penitrem A in Dogs}

The elimination half-life of penitrem $A$ in the dog liver microsome assay $\left(t_{1 / 2, \text { assay }}\right)$ and the assay clearance $\left(\mathrm{CL}_{\text {assay}}\right)$ were calculated from the $\mathrm{k}_{\mathrm{e}}$ and used to determine the intrinsic assay clearance $\left(\mathrm{CL}_{\text {int,assay }}\right)$, which gave a measure for the phase I enzyme activities in the microsomes (Table 3 ). The $\mathrm{CL}_{\text {int,assay }}$ was upscaled to the assay-independent, intrinsic liver clearance $\left(\mathrm{CL}_{\text {int }}\right)$ by considering the microsomal protein amount and dog-specific upscaling factors for relative liver weight and microsomal recovery index $[33,34]$. IVIVE predicting the in vivo blood clearance $\left(\mathrm{CL}_{\mathrm{b}}\right)$ was performed by using the well-stirred liver model under consideration of the hepatic blood flow in dog [30]. With $0.9(\mathrm{~L} /(\mathrm{h} \times \mathrm{kg}))$, the $\mathrm{CL}_{\mathrm{b}}$ is considered intermediate to low, indicating that penitrem $\mathrm{A}$ is eliminated with medium velocity in dogs. Our prediction fitted thus with the in vivo-observed maximum toxic effect at about $30 \mathrm{~min}$ after intoxication [9]. Calculation of the maximal bioavailability $\left(\mathrm{f}_{\max }=57 \%\right)$ after oral application under the assumption of complete absorption from the gastrointestinal tract supported the assumption that a considerable amount of penitrem A reaches the systemic circulation after the first pass through the liver [35].

Table 3. Predicted toxicokinetic parameters for penitrem A in dogs by in vitro-to-in vivo extrapolation from incubations with dog liver microsomes.

\begin{tabular}{cc}
\hline Parameter & Dog Liver Microsomes \\
\hline $\mathrm{k}_{\mathrm{e}}\left(\min ^{-1}\right)$ & 0.03 \\
$\mathrm{t}_{1 / 2 \text {,assay }}(\mathrm{min})$ & 23.1 \\
$\mathrm{~K}_{\mathrm{M} \text {,assay }}(\mu \mathrm{M})$ & 12 \\
$\mathrm{CL}_{\text {int,assay }}(\mathrm{L} / \mathrm{h})$ & $1.8 \times 10^{-3}$ \\
$\mathrm{CL}_{\text {int }}\left(\mathrm{L} /\left(\mathrm{h}^{*} \mathrm{~kg}\right)\right)$ & 1.6 \\
$\mathrm{CL}_{\mathrm{b}}\left(\mathrm{L} /\left(\mathrm{h}^{*} \mathrm{~kg}\right)\right)$ & 0.9 \\
$\mathrm{f}_{\max }(\%)$ & 57 \\
\hline
\end{tabular}




\section{Conclusions}

Penitrem A poisoning affects mostly dogs due to their feeding behavior and access to moldy food. Whereas the clinical symptoms of an intoxication are well-known, there are practically no data on the biotransformation and toxicokinetics of the toxin in dogs. In the present study, we have used HRMS to detect eleven penitrem A phase I-metabolites in incubations with dog liver microsomes. The identified metabolites included several isomers of mono- and di-oxygenated as well as hydrated products. They were confirmed in the plasma of a dog that had been exposed to penitrem A. Moreover, we applied in vitro-to-in vivo extrapolation of the substrate depletion data to predict important toxicokinetic parameters. The bioavailability of penitrem A is expected to be considerable and the blood clearance low enough to allow reaching a substantial toxin level in the systemic circulation.

\section{Materials and Methods}

\subsection{Chemicals and Reagents}

Crystalline penitrem A ( $\geq 95 \%)$, magnesium chloride hexahydrate, glucose-6-phosphate sodium salt, $\beta$-nicotinamide adenine dinucleotide phosphate sodium salt $\left(\mathrm{NADP}^{+}\right), \beta$-nicotinamide adenine dinucleotide phosphate reduced tetrasodium salt (NADPH), glucose-6-phosphate dehydrogenase, HEPES buffer and ammonium formate were from Sigma-Aldrich (Merck KGaA, Darmstadt, Germany). Water and acetonitrile (MeCN) for LC-MS were of Optima grade (Thermo Fisher Scientific, Waltham, MA, USA). Methanol (MeOH) and MeCN for other purposes than LC-MS were of gradient quality and from Romil (Cambridge, UK).

\subsection{Microsomal Incubations}

Substrate depletion assays measuring the concentration-time course of penitrem A were performed with commercially available dog liver microsomes (No. M00201, Lot \#ORT, 20 mg/mL; Celsis, Baltimore, MD, USA) under conditions of first-order kinetics to determine assay half-life ( $\left.t_{1 / 2 \text {,assay }}\right)$ for the extrapolation of toxicokinetic parameters. In vitro assays at higher concentrations were used to produce sufficient amounts of penitrem A metabolites for structure elucidation and identification.

From a penitrem A stock solution $(0.5 \mathrm{mg} / \mathrm{mL}$ in $\mathrm{MeOH}, 790 \mu \mathrm{M})$, concentrated aliquots and dilutions were prepared in order to obtain final concentrations of $0.3,1.2,2.5,10$, and $20 \mu \mathrm{M}$ in the microsomal assay. The proportion of organic solvent in the microsomal assay was less than $0.3 \%$. The penitrem A solutions were added to $1 \mathrm{~mL}$ reaction mixture containing $2 \mathrm{mg} / \mathrm{mL}$ microsomes and an NADPH generating system (1 mM NADPH, $1 \mathrm{mM} \mathrm{NADP}{ }^{+}, 20.9 \mathrm{mM}$ glucose 6-phosphate, $1 \mathrm{U} / \mathrm{mL}$ glucose-6-phosphate dehydrogenase, $9 \mathrm{mM} \mathrm{MgCl}_{2} \times\left(\mathrm{H}_{2} \mathrm{O}\right)_{6}, 49 \mathrm{mM} \mathrm{HEPES} \mathrm{pH} \mathrm{7.4)} \mathrm{after}$ preincubation at $37^{\circ} \mathrm{C}$ for $3 \mathrm{~min}$ in a shaking water bath (OLS 200; Grant, Cambridge, UK). The reaction tube was vortexed for $15 \mathrm{~s}$ and further incubated under shaking.

Aliquots of $130 \mu \mathrm{L}$ were taken after $0,5,10,15,30$ and $60 \mathrm{~min}$ and transferred to Eppendorf tubes containing equal volumes of ice-cold $100 \% \mathrm{MeCN}$. Samples were vortexed for $15 \mathrm{~s}$ and kept on ice until centrifugation at $20,000 \times \mathrm{g}$ for $10 \mathrm{~min}$ at $4{ }^{\circ} \mathrm{C}$ to precipitate proteins (Eppendorf, Hamburg, Germany). Supernatants were filtered through $0.22 \mu \mathrm{m}$ Nylon Costar Spin-X tubes (Corning Inc., Corning, NY, USA) by centrifugation at $15,000 \times g$ for $1 \mathrm{~min}$ and transferred to chromatography vials for LC-ITMS analysis.

Penitrem A biotransformation products were concentrated prior to LC-HRMS analyses. Aliquots from the microsomal assay, taken between 10 to $60 \mathrm{~min}$ from incubations with $1.2 \mu \mathrm{M}$ and $2.5 \mu \mathrm{M}$ start concentrations were pooled $(3.05 \mathrm{~mL}$ in total) in a conical tube. Most of the MeCN was evaporated at $50{ }^{\circ} \mathrm{C}$ under a nitrogen stream, and evaporation was stopped when the solvent level reached $1.8 \mathrm{~mL}$. Ethyl acetate (1.8 mL; Rathburn Chemicals, Walkerburn, Scotland) was then added and vortexed for $1 \mathrm{~min}$. After phase separation, the upper layer was carefully pipetted into a new tube. The ethyl acetate phase was evaporated to dryness, and the residue dissolved in $250 \mu \mathrm{L} 80 \% \mathrm{MeOH}$ and transferred to a HPLC vial. 


\subsection{Determination of Toxicokinetic Parameters In Vitro and Upscaling to In Vivo}

The biotransformation assays were run under the conditions of first-order kinetics to allow the calculation of kinetic parameters for upscaling to in vivo. The activity of the microsomal enzymes can be described by the Michaelis-Menten equation parameters' maximum velocity ( $\left.v_{\text {max,assay }}\right)$ and reaction constant $\left(\mathrm{K}_{\mathrm{M} \text {,assay }}\right)$ if the substrate concentration is well below the $\mathrm{K}_{\mathrm{M}}$ value $\left(C L_{\text {int,assay }}=\right.$ $\mathrm{v}_{\max \text {,assay }} / \mathrm{K}_{\mathrm{M} \text {,assay }}$ ). As a first step, the $\mathrm{K}_{\mathrm{M}}$ of penitrem A depletion in dog liver microsomes was approximated by using rate constants $\left(\mathrm{k}_{\mathrm{e}}\right)$ that were determined by regression analysis of measured peak areas versus time curves in experiments with different penitrem A start concentrations $(0.3$, $1.2,2.5,10$ and $20 \mu \mathrm{M})$. The inflection point of a lin-log $\mathrm{k}_{\mathrm{e}}$ versus concentration curve is equivalent to $\mathrm{K}_{\mathrm{M}}$, occurring when $\mathrm{k}_{\mathrm{e}}$ is half of the theoretical maximum $\mathrm{k}_{0}$ at infinitesimally low penitrem $\mathrm{A}$ concentrations [32]. The $\mathrm{k}_{\mathrm{e}}$ of incubations with low starting concentration were subsequently used to calculate the assay half-life $\left(\mathrm{t}_{1 / 2, \text { assay }}=\ln 2 / \mathrm{k}_{\mathrm{e}}\right)$ and, under consideration of the assay volume $\left(\mathrm{V}_{\text {assay }}\right)$, the assay clearance $\left(\mathrm{CL}_{\text {assay }}=\mathrm{V}_{\text {assay }} \times \mathrm{k}_{\mathrm{e}}\right)$, which was close to the intrinsic assay clearance $\left(\mathrm{CL}_{\text {int,assay }}\right)$, if protein binding of the substrate in the reaction mixture could be neglected.

The assay-independent intrinsic liver clearance $\left(\mathrm{CL}_{\text {int }}=\mathrm{CL}_{\text {int,assay }} \times \mathrm{MRI} \times \mathrm{RLW} / \mathrm{Prot}_{\text {assay }}\right)$ for penitrem $\mathrm{A}$ in dogs was calculated under consideration of the amount of microsomal protein in

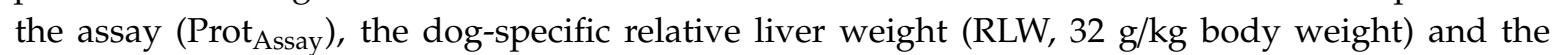
microsomal recovery index (MRI, $55 \mathrm{mg} / \mathrm{g}$ liver) $[33,34]$. The systemic blood clearance $\left(\mathrm{CL}_{\mathrm{b}}\right)$ was then determined by using the well-stirred liver model $\left(\mathrm{CL}_{\mathrm{b}}=\mathrm{Q} \times \mathrm{CL}_{\text {int }} /\left(\mathrm{Q}+\mathrm{CL}_{\text {int }}\right)\right.$ from the hepatic blood flow in $\operatorname{dogs}(\mathrm{Q}, 2.1 \mathrm{~L} / \mathrm{h} \times \mathrm{kg}$ bodyweight $)$ without consideration of binding to blood proteins [30,35]. The maximal bioavailability $\left(f_{\max }\right)$ after oral application was calculated under the assumption of complete absorption from the gastrointestinal tract $\left(\mathrm{f}_{\max }=1-\mathrm{CL}_{\mathrm{b}} / \mathrm{Q}\right)[35]$.

\subsection{LC-ITMS}

Low-resolution mass spectrometry data were acquired using an LTQ linear ion trap mass spectrometer equipped with an atmospheric pressure chemical ionization (APCI) interface, and a Finnigan Surveyor MS Pump Plus and Accela autosampler (all Thermo Fisher Scientific). Aliquots from microsomal incubations were separated using a Kinetex XB-C18 column $(100 \times 4.6 \mathrm{~mm}, 2.6 \mu \mathrm{m}$ particles; Phenomenex, Torrance, CA, USA) held at $30{ }^{\circ} \mathrm{C}$ with mobile phases A and B of water and $95 \% \mathrm{MeCN}$, respectively, both containing $2 \mathrm{mM}$ ammonium formate, at a flow rate of $0.7 \mathrm{~mL} \mathrm{~min}{ }^{-1}$. The column was eluted isocratically for $0.5 \mathrm{~min}$ with $30 \% \mathrm{~B}$ followed by a linear gradient increasing from $30 \%$ to $80 \%$ B in $17 \mathrm{~min}$ and finally to $95 \% \mathrm{~B}$ in $0.5 \mathrm{~min}$. After flushing the column with $95 \%$ B for $3.5 \mathrm{~min}$, the mobile phase was returned to $30 \% \mathrm{~B}$ in $0.5 \mathrm{~min}$ and re-equilibrated for $3.5 \mathrm{~min}$. The mass spectrometer was operated in full scan ion mode $(\mathrm{m} / \mathrm{z} 400-800)$, and the APCI interface in the positive ionization mode. The parameters for APCI were: vaporization temperature $400{ }^{\circ} \mathrm{C}$, sheath gas flow 43 units nitrogen, auxiliary gas rate 7 units nitrogen, sweep gas flow rate 0 units, source voltage $6 \mathrm{kV}$, tube lens offset $90 \mathrm{~V}$, capillary voltage $31 \mathrm{~V}$ and capillary temperature $200^{\circ} \mathrm{C}$. Toxicokinetic calculations were based on peak areas of the protonated molecules of penitrem A observed at $m / z$ 634.2.

\subsection{LC-HRMS and HRMS/MS}

High-resolution mass spectrometry data with the aim to tentatively characterize penitrem A biotransformation products were collected using a Q-Exactive Quadrupole Orbitrap mass spectrometer equipped with a HESI-II heated electrospray ionization interface, and a Vanquish Horizon UHPLC pump, including an autosampler and column oven (all Thermo Fisher Scientific). Separation was achieved using a Kinetex EVO C18 column $(100 \times 2.1 \mathrm{~mm}, 2.6 \mu \mathrm{m}$; Phenomenex $)$ held at $30^{\circ} \mathrm{C}$ with mobile phases A and B of water and $95 \% \mathrm{MeCN}$, respectively, both containing $2 \mathrm{mM}$ ammonium formate, at a flow rate of $0.3 \mathrm{~mL} \mathrm{~min}^{-1}$. The penitrem A metabolites were chromatographically resolved by isocratic elution for $0.5 \mathrm{~min}$ at $30 \% \mathrm{~B}$ followed by a linear gradient increasing from $30 \%$ to $80 \% \mathrm{~B}$ in $16.5 \mathrm{~min}$ and finally to $95 \% \mathrm{~B}$ in $0.5 \mathrm{~min}$. After washing the column at $95 \%$ B for $3.5 \mathrm{~min}$, 
the mobile phase was returned to $30 \% \mathrm{~B}$ in $0.5 \mathrm{~min}$ and re-equilibrated for $3.5 \mathrm{~min}$. The total run time was $25 \mathrm{~min}$. The conditions for positive HESI were as follows: capillary voltage, $3.5 \mathrm{kV}$; capillary temperature, $280^{\circ} \mathrm{C}$; sheath gas and auxiliary gas flow, 35 and 10 units, respectively; probe heater temperature, $300{ }^{\circ} \mathrm{C}$; S-lens RF level, 55. The mass spectrometer was run in the Full-MS mode (scan range $m / z 400-800$ ) at a mass resolution set to 70,000 at $m / z 200$. The Full-MS scan was alternated with all-ion-fragmentation (AIF) of the ions in the same mass range, and product ions were scanned in the range $m / z$ 80-800. The maximum target capacity of the C-trap (AGC target) was set to $3 \times 10^{6}$ and the maximum injection time to $200 \mathrm{~ms}$. Parallel reaction monitoring was performed using a mass resolution of 35,000 at $\mathrm{m} / \mathrm{z} 200$, an AGC target of $2 \times 10^{5}$ and a maximum injection time of $100 \mathrm{~ms}$. Precursor ions were selected with an isolation width of $m / z 1.5$ and fragmented using a normalized collision energy of 35 units. Product ions were scanned in the range $m / z 50-735$. Xcalibur (Thermo Fisher Scientific), version 2.3 was used for instrument control, while version 4.2 was used for data processing and calculation of elemental compositions.

\subsection{Preparation of Stomach Contents and Plasma Samples from Potentially Intoxicated Dogs}

Blood samples were obtained from four dogs suspected to suffer from acute penitrem A poisoning (Table 4). In addition, stomach contents were available from one of the dogs.

Table 4. Sample types and background information for four dogs with suspected penitrem poisoning.

\begin{tabular}{ccccc}
\hline Dog nr. & Sampling Date & Available Samples & Origin & Penitrem A \\
\hline 1 & 14 February 2018 & Plasma, stomach contents & Fredrikstad ${ }^{1}$ animal clinic & positive \\
2 & 25 February 2018 & Plasma & Fredrikstad animal clinic & negative \\
3 & 22 January 2018 & Serum & Fredrikstad animal clinic & negative \\
4 & 1 April 2018 & Plasma & NMBU ${ }^{2}$ small animal clinic & negative \\
\hline \multicolumn{5}{r}{${ }^{1}$ Fredrikstad, Norway; ${ }^{2}$ NMBU: Norwegian University of Life Sciences, Oslo, Norway. }
\end{tabular}

Stomach contents (ca. $13 \mathrm{~g}$ ) were transferred to a $250 \mathrm{~mL}$ Beckmann centrifuge flask and $50 \mathrm{~mL}$ of $80 \% \mathrm{MeCN}$ were added. The mixture was shaken for $20 \mathrm{~min}$ on an orbital shaker $\left(250 \mathrm{~min}^{-1}\right)($ Edmund Bühler, Bodelshausen, Germany) and centrifuged in a Beckman J2-MC centrifuge (Beckman Coulter Life Sciences, Indianapolis, IN, USA) for $5 \mathrm{~min}$ at $2400 \times g$. An aliquot $(500 \mu \mathrm{L})$ of the supernatant was filtered through $0.22 \mu \mathrm{m}$ Nylon Costar Spin-X tubes (Costar, Corning Inc., Corning, NY, USA) at 20,000 $\times g$ and $4{ }^{\circ} \mathrm{C}$, transferred to an HPLC vial and submitted to LC-HRMS analysis.

Aliquots of blood plasma or serum $(250 \mu \mathrm{L})$ were transferred to Eppendorf tubes containing $250 \mu \mathrm{L}$ ice-cold $100 \% \mathrm{MeCN}$ and vortexed for $30 \mathrm{~s}$. After centrifugation at 20,000× $g$ for $3 \mathrm{~min}$ at $4{ }^{\circ} \mathrm{C}$ (MicroCL 21R, Thermo Fisher Scientific), the supernatant was transferred to HPLC vials and submitted to LC-HRMS analysis.

\subsection{Anamnesis of the Penitrem A-Positive Dog}

Shortly after the owner had observed unusual behavior, he took the dog to the veterinary clinic at 10:30 pm. The dog had seizures, mydriasis, nystagmus and opisthotonos. Heparin plasma was taken for mycotoxin analysis, as well as other analyses, before medical treatment for seizures was started immediately. On clinical examination, the dog showed severe signs of depression, which made further neurological examinations difficult. Further indicators for a neurotoxic poisoning were posterior paresis and reduced or lacking withdrawal reflexes. The body temperature, heart rate and respiratory rate were normal. The only aberration found was a slight hyperglycemia. The dog alternated sleeping with tendencies of tremors and seizures during the night. At 10:00 am, the dog "awakened" and appeared more responsive, still having some tremors. Although still paretic and ataxic, there was a slight tendency of tonus in all four limbs. The dog was interested in feed and was able to swallow normally. It didn't receive any medication and left the veterinary clinic the day after admission, making a full recovery. 
Author Contributions: Conceptualization, L.I., S.U. and C.K.F.; methodology, L.I., C.K.F. and S.U.; software, L.I. and S.U.; validation, L.I., C.K.F. and S.U.; formal analysis, L.I., S.U. and P.V.; investigation, L.I., S.U. and P.V.; resources, S.U. and P.V.; data curation, S.U. and C.K.F.; writing-original draft preparation, S.U., L.I., P.V. and C.K.F.; writing-review and editing, S.U. and C.K.F.; visualization, S.U., L.I., and C.K.F.; supervision, S.U., L.I. and C.K.F.; project administration, S.U. and C.K.F.; funding acquisition, P.V. and S.U. All authors have read and agreed to the published version of the manuscript.

Funding: This research received no external funding. It has been carried out as part of Pauline Voorspoels' master thesis in pharmacy in a collaboration between Ghent University, Ghent, Belgium, and the Norwegian Veterinary Institute, Oslo, Norway.

Acknowledgments: We are grateful to Sarah de Saeger from the Department of Bioanalysis at Ghent University, Belgium, for supporting this project as the promoter of the master thesis of Pauline Voorspoels. We would also like to thank Helene Wisløff at the Norwegian Veterinary Institute for translating the anamnesis of the penitrem A-positive dog. Finally, our sincere thanks go to the owners of the four dogs included in this study who agreed to submit samples for penitrem A analysis.

Conflicts of Interest: The authors declare no conflict of interest.

\section{References}

1. Richard, J.L.; Arp, L.H. Natural occurrence of the mycotoxin penitrem A in moldy cream cheese. Mycopathologia 1997, 67, 107-109.

2. Cole, R.J.; Dorner, J.W.; Cox, R.H.; Raymond, L.W. Two classes of alkaloid mycotoxins produced by Penicillium crustosum Thom isolated from contaminated beer. J. Agric. Food Chem. 1983, 31, 655-657. [CrossRef] [PubMed]

3. Patterson, D.S.; Roberts, B.A.; Shreeve, B.J.; MacDonald, S.M.; Hayes, A.W. Tremorgenic toxins produced by soil fungi. Appl. Environ. Microbiol. 1979, 37, 172-173. [CrossRef] [PubMed]

4. Scuteri, M.; Sala de Miguel, M.A.; Viera, J.B.; de Banchero, E.P. Tremorgenic mycotoxins produced by strains of Penicillium spp. isolated from toxic Poa huecu parodi. Mycopathologia 1992, 120, 177-182. [CrossRef]

5. Kozák, L.; Szilágyi, Z.; Tóth, L.; Pócsi, I.; Molnár, I. Tremorgenic and neurotoxic paspaline-derived indole-diterpenes: Biosynthetic diversity, threats and applications. Appl. Microbiol. Biotechnol. 2019, 103, 1599-1616. [CrossRef]

6. Moldes-Anaya, A.S.; Fonnum, F.; Eriksen, G.S.; Rundberget, T.; Walaas, S.I.; Wigestrand, M.B. In vitro neuropharmacological evaluation of penitrem-induced tremorgenic syndromes: Importance of the GABAergic system. Neurochem. Int. 2011, 59, 1074-1081. [CrossRef] [PubMed]

7. Berntsen, H.F.; Bogen, I.L.; Wigestrand, M.B.; Fonnum, F.; Walaas, S.I.; Moldes-Anaya, A. The fungal neurotoxin penitrem $\mathrm{A}$ induces the production of reactive oxygen species in human neutrophils at submicromolar concentrations. Toxicology 2017, 392, 64-70. [CrossRef]

8. Sobotka, T.J.; Brodie, R.E.; Spaid, S.L. Neurobehavioral studies of tremorgenic mycotoxins verruculogen and penitrem A. Pharmacology 1978, 16, 287-294. [CrossRef]

9. Eriksen, G.S.; Moldes-Anaya, A.; Fæste, C.K. Penitrem A and analogues: Toxicokinetics, toxicodynamics including mechanism of action and clinical significance. World Mycotox. J. 2013, 6, 263-272. [CrossRef]

10. Talcott, P.A. Tremorgens (Penitrem A and Roquefortine). In Small Animal Toxicology, 3rd ed.; Peterson, M.E., Talcott, P.A., Eds.; Elsevier Inc.: Amsterdam, The Netherlands, 2013; pp. 677-682.

11. Lewis, P.R.; Donoghue, M.B.; Hocking, A.D.; Cook, L.; Granger, L.V. Tremor syndrome associated with fungal toxin: Sequelae of food contamination. Med. J. Aust. 2005, 182, 582-584. [CrossRef]

12. Hayes, A.W.; Presley, D.B.; Neville, J.A. Acute toxicity of penitrem A in dogs. Toxicol. Appl. Pharmacol. 1976, 35, 311-320. [CrossRef]

13. Richard, J.L.; Bacchetti, P.; Arp, L.H. Moldy walnut toxicosis in a dog, caused by the mycotoxin, penitrem A. Mycopathologia 1981, 76, 55-58. [CrossRef] [PubMed]

14. Hocking, A.D.; Holds, K.; Tobin, N.F. Intoxication by tremorgenic mycotoxin (penitrem A) in a dog. Aust. Vet. J. 1988, 65, 82-85. [CrossRef] [PubMed]

15. Walter, S.L. Acute penitrem A and roquefortine poisoning in a dog. Can. Vet. J. Rev. Vet. Can. 2002, 43, 372-374.

16. Naude, T.W.; O’Brien, O.M.; Rundberget, T.; McGregor, A.D.; Roux, C.; Flåøyen, A. Tremorgenic neuromycotoxicosis in 2 dogs ascribed to the ingestion of penitrem $\mathrm{A}$ and possibly roquefortine in rice contaminated with Penicillium crustosum. J. S. Afr. Vet. Assoc. 2002, 73, 211-215. [CrossRef] 
17. Boysen, S.R.; Rozanski, E.A.; Chan, D.L.; Grobe, T.L.; Fallon, M.J.; Rush, J.E. Tremorgenic mycotoxicosis in four dogs from a single household. J. Am. Vet. Med. Assoc. 2002, 221, 1441-1444. [CrossRef]

18. Young, K.L.; Villar, D.; Carson, T.L.; Ierman, P.M.; Moore, R.A.; Bottoff, M.R. Tremorgenic mycotoxin intoxication with penitrem A and roquefortine in two dogs. J. Am. Vet. Med. Assoc. 2003, 222, 52-53. [CrossRef]

19. Munday, J.S.; Thompsom, D.; Finch, S.C.; Babu, J.V.; Wilkins, A.L.; Di Menna, M.E.; Miles, C.O. Presumptive tremorgenic mycotoxicoses in a dog in New Zealand, after eating mouldy walnuts. N. Z. Vet. J. 2008, 56, 145-147. [CrossRef]

20. Eriksen, G.S.; Jäderlund, K.H.; Moldes-Anaya, A.; Schönheit, J.; Bernhoft, A.; Jæger, G.; Rundberget, T.; Skaar, I. Poisoning of dogs with tremorgenic Penicillium toxins. Med. Mycol. 2010, 48, 188-196. [CrossRef]

21. Evans, T.J.; Gupta, R.C. Tremorgenic Mycotoxins. In Veterinary Toxicology, 3rd ed.; Gupta, R.C., Ed.; Academic Press: New York, NY, USA, 2018; pp. 1033-1041.

22. Chapman, E. Nursing a canine with presumptive tremorgenic mycotoxicosis following ingestion of mouldy dog food-a case report. Vet. Nurs. J. 2018, 33, 166-169. [CrossRef]

23. Barker, A.K.; Stahl, C.; Ensley, S.M.; Jeffery, N.D.; Decus, D. Tremorgenic mycotoxicosis in dogs. Compend. Contin. Educ. Vet. 2013, 35, E2. [PubMed]

24. Goda, A.A.; Naguib, K.M.; Mohamed, M.M.; Amra, H.A.; Nada, S.A.; Abdel-Ghaffar, A.R.B.; Gissendanner, C.R.; El Sayed, K.A. Astaxanthin and docosahexaenoic acid reverse the toxicity of the maxi-K (BK) channel antagonist mycotoxin penitrem A. Mar. Drugs 2016, 14, 208. [CrossRef] [PubMed]

25. Rundberget, T.; Wilkins, A.L. Determination of Penicillium mycotoxins in foods and feeds using liquid chromatography-mass spectrometry. J. Chromatogr. A 2002, 964, 189-197. [CrossRef]

26. Tor, E.R.; Puschner, B.; Filigenzi, M.S.; Tiwary, A.K.; Poppenga, R.H. LC-MS/MS screen for penitrem A and roquefortine $C$ in serum and urine samples. Analyt. Chem. 2006, 78, 4624-4629. [CrossRef]

27. Moldes-Anaya, A.; Wilkins, A.L.; Rundberget, T.; Fæste, C.K. In vitro and in vivo hepatic metabolism of the fungal neurotoxin penitrem A. Drug Chem. Toxicol. 2009, 32, 26-37. [CrossRef]

28. Moldes-Anaya, A.; Rundberget, T.; Fæste, C.K.; Eriksen, G.S.; Bernhoft, A. Neurotoxicity of Penicillium crustosum secondary metabolites: Tremorgenic activity of orally administered penitrem A and thomitrem A and $\mathrm{E}$ in mice. Toxicon 2012, 60, 1428-1435. [CrossRef]

29. Kalinina, S.A.; Jagels, A.; Hickert, S.; Mauriz Marques, L.M.; Cramer, B.; Humpf, H.U. Detection of the cytotoxic penitrems A-F in cheese from the European single market by HPLC-MS/MS. J. Agric. Food Chem. 2018, 66, 1264-1269. [CrossRef]

30. Ito, K.; Houston, B. Prediction of human drug clearance from in vitro and preclinical data using physiologically based and empirical approaches. Pharm. Res. 2005, 22, 103-112. [CrossRef]

31. Iwatsubo, T.; Hirota, N.; Ooie, T.; Suzuki, H.; Shimada, N.; Chiba, K.; Ishizaki, T.; Green, C.E.; Tyson, C.A.; Sugiyama, Y. Prediction of in vivo drug metabolism in the human liver from in vitro metabolism data. Pharmacol. Ther. 1997, 73, 147-171. [CrossRef]

32. Obach, R.S.; Reed-Hagen, A.E. Measurement of Michaelis constant for cytochrome P450-mediated biotransformation reactions using a substrate depletion approach. Drug Met. Disp. 2002, 30, 831-837. [CrossRef]

33. Lindstedt, S.L.; Schaeffer, P.J. Use of allometry in predicting anatomical and physiological parameters of mammals. Lab. Anim. 2002, 36, 1-19. [CrossRef] [PubMed]

34. Smith, R.; Jones, R.D.O.; Ballard, P.G.; Griffiths, H.H. Determination of microsome and hepatocyte scaling factors for in vitro/in vivo extrapolation in the rat and dog. Xenobiotica 2008, 38, 1386-1398. [CrossRef] [PubMed]

35. Obach, R.S.; Baxter, J.G.; Listin, T.E.; Silber, B.M.; Jones, B.C.; MacIntyre, F.; Ranve, D.J.; Wastall, P. The prediction of human pharmacokinetic parameters from preclinical and in vitro metabolism data. J. Pharmacol. Exp. Ther. 1997, 283, 46-58. [PubMed]

(C) 2020 by the authors. Licensee MDPI, Basel, Switzerland. This article is an open access article distributed under the terms and conditions of the Creative Commons Attribution (CC BY) license (http://creativecommons.org/licenses/by/4.0/). 